Int. Z. angew. Physiol. 31, 197-207 (1973)

(C) by Springer-Verlag 1973

\title{
Kinetics of Oxygen Uptake and Recovery for Supramaximal Work of Short Duration
}

\author{
Victor L. Katch \\ Research Laboratories, Department of Physical Education, \\ The University of Michigan, Ann Arbor, Michigan 48104, U.S.A.
}

Received September 19, 1972

\begin{abstract}
In order to follow the time pattern of oxygen uptake and recovery for supramaximal work of short duration, 35 male subjects (mean age 21.4 years, mean body weight $71.9 \mathrm{~kg}$ ) pedalled a bicycle ergometer at maximal speed for 1 min. A constant frictional resistance of $5.5 \mathrm{~kg}$ was used, resulting in a total work output of $2890 \mathrm{kpm}$ ( 85 revolutions, $\mathrm{SD}=7.5$ ). The total percent decrement in work output from the initial rate on this test was $59.7 \%$. The total oxygen uptake during the work averaged $2.35 \mathrm{l}$, the net oxygen recovery was $4.89 \mathrm{l}$, while the net work efficiency was $19.3 \%$. One and two component exponential curves fit the observed oxygen uptake and recovery measures with a high degree of accuracy. Comparison of the curve parameters with published data showed large differences for the post exercise oxygen recovery and the slow component of the recovery curve. The magnitude of the fast component of recovery was similar to other data. The total oxygen uptake during the test was found to be $10 \%$ lower than the maximal oxygen uptake determined on a seperate progressive step-increment test. It was shown, by curve analysis, that the maximal oxygen uptake would have been reached in approximately $2 \mathrm{~min}$.
\end{abstract}

Key words: $\mathrm{O}_{2}$ Uptake $-\mathrm{O}_{2}$ Debt — Supramaximal Work.

The kinetics of oxygen uptake during exercise and recovery have been studied for light $[2,9,13,15,28,34]$, moderate $[7,8,14,16,21$, $24,26]$, and moderately heavy work $[16,19,23,25]$ of various durations. Depending on the intensity of the exercise, either a single or double component exponential equation has been found to describe the time pattern of oxygen uptake during the exercise and subsequent recovery. The derivation and explanation of the exponential formula can be found in several reports $[9,15,16,20,26,34]$. Briefly, the equation states that the rate of oxygen uptake $(Y)$ at any time $t$ of exercise is given by the equation:

$$
Y=C-a_{1} e^{-k_{1} t}+a_{2} e^{-k_{2} t},
$$

where, $C$ is the resting oxygen uptake $+\left(a_{1}+a_{2}\right), a_{1}+a_{2}$ represent the steady-level oxygen uptake above rest, and the exponentials equal the 
amount of oxygen uptake. During recovery, the negative term changes to positive, $C$ equals resting oxygen uptake, $a_{1}+a_{2}$ represents the amount of oxygen uptake at $t=0$ (end of exercise and beginning of recovery), and the exponentials represent the fast and slow pay-off components first described by Hill et al. [16] and Margaria et al. [26].

In the 1920's interpretation of the exponential uptake and recovery curves were based on the assumed time course of lactate accumulation and disappearance [16]. In 1933, Margaria [26] et al. demonstrated that the fast component of the recovery curve was not responsible for this lactate disappearance but was related to the oxidation of substances furnishing the energy for the resynthesis of phosphagens split during muscular contraction.

The fast component $\left(a_{1} e^{-k_{1} t}\right)$, which has been shown to be approximately a linear function of the oxygen uptake in exercise [14, 26], as well as the slower 'lactacid' component $\left(a_{2} e^{-k_{2} t}\right)$ have been studied by numerous investigators for light to moderate work $[1,3,8,20,21,24$, $27,29,33]$. There are, however, very little data on the magnitude of these two exponential components, as well as the time pattern of oxygen uptake during exercise and recovery for extremely heavy work (supra maximal work) of short duration where only a very small portion of the energy requirement is met by aerobic metabolism. It has been pointed out by Margaria [24] that during such work (as for example cycling against a very heavy resistance at maximal speed for 40 to 60 sec) an individual will reach his anaerobic capacity. Thus, it is possible that the kinetics of oxygen uptake for this exercise and recovery will be quite different than it is for light or moderately heavy exercise conditions, possibly due to such factors as increased lactate production [23], extra oxygen cost of ventilation [32], or increased temperature during recovery [3].

Therefore, the aim of the present study is to examine the kinetics (time pattern) of oxygen uptake during exercise and recovery for supramaximal work of short duration.

\section{Methods}

Subjects. Thirty-five male college students served as subjects. The mean age was 21.4 years $(\mathrm{SD}=2.4$ ) and mean weight $71.9 \mathrm{~kg}(\mathrm{SD}=7.5)$. These were all volunteer subjects from the general physical activities program of the University. Students involved in intercollegiate athletics, or who were participating in a conditioning program were omitted from the sample.

Supramaximal Work of Short Duration. Each subject rode a Monarch bicycle ergometer (Sweden) for $1 \mathrm{~min}$ as fast as possible with a constant frictional resistance of $5.5 \mathrm{~kg} /$ revolution. The choice of this workload was based on the observation that subjects are able to accomplish more work perunit time with this particular rate-profile (resistance $\times$ pedal frequency) than one involving a greater or lesser 
frictional resistance, and hence, a different number of pedal revolutions (B. Edwards, unpublished data). Also, the data of Margaria et al. [23, 24] suggests that if individuals work as rapidly as possible for 40 to $60 \mathrm{sec}$ at a comparable work-rate, the anaerobic capacity will be attained.

Prior to the beginning, and during the test, the subjects were not told the exact duration of the test, only that it was very short and they were to attempt to turn as many revolutions as possible. This is important since preliminary data indicated that when subjects know the duration of the work, they tend to pace themselves and don't produce an initial all-out effort.

Starting with the pedals in a horizontal position with minimal friction, on the command Ready-Go, the subjects began pedalling as fast as possible. The frictional resistance was immediately increased to the desired setting and remained through out the test. It was necessary to start at zero friction because of the difficulty in overcoming the inertial factors with such a high frictional resistance. The time delay from the command $G o$ to the setting of the proper friction load was 1 to 2 sec. An electrical counter activated by each pedal revolution made it possible to monitor the exact work-rate profile of each subject.

Expired air samples were continuously collected by the open eircuit method described elsewhere [18], during $2 \mathrm{~min}$ of rest, during exercise, and for $15 \mathrm{~min}$ of recovery. The number of aliquot samples of expired air and time of collection were:

2-1 min resting samples;

3-20 sec exercise samples;

6-20 sec recovery samples (first $2 \mathrm{~min}$ of recovery);

13 - 1 min recoverg samples.

The samples of expired air were analyzed using a Beckman E-2 oxygen analyzer and LB-1, $\mathrm{CO}_{2}$ analyzer. These instruments were calibrated before each experiment using commercially prepared gas mixtures which were checked using the Haldane apperatus and technique. During the recovery period (between 3 and $5 \mathrm{~min}$ ), a stool with a foam cushion was slipped over the bicycle seat to insure added comfort.

$V_{\mathbf{0}_{2}}$ Max Test. Maximal oxygen uptake was determined on a progressive workload increment test on the bicyole ergometer. Subjects pedalled at a relatively constant rate of $60 \mathrm{rpm}$ paced by an auditory-visual metranome with a starting friction load of $900 \mathrm{kpm} / \mathrm{min}$. Every $2 \mathrm{~min}$ thereafter the frictional resistance was increased $120 \mathrm{kpm} / \mathrm{min}$ until the subject stopped pedalling.

Prior to the start of each test, the subjects practiced pedalling at $540 \mathrm{kpm} / \mathrm{min}$ in order to become accustomed to the pace. Each subject was encouraged to pedal for as long as possible. Strong vocal encouragement was given throughout the test with the intent of pushing the subject to attain his highest work output.

Minute-by-minute oxygen uptake was measured simultaneously during each minute of ergometer work by the method described earlier. $V_{0_{2}}$ max was chosen as the highest value in the series of oxygen scores on each individual.

\section{Results and Discussion}

Performance and Metabolic Measures. The total number of pedal revolutions turned for the 35 subjects was $85.0(S D=7.5)$. When this value is multiplied by the work per pedal revolution $34.0 \mathrm{kp}(5.5 \mathrm{~kg}$ $\times$ gear ratio of 6$)$, it equals $2890.0 \mathrm{kpm}(\mathrm{SD}=255.0)$. The percent decrement in work-rate from the initial rate is $59.7 \%$. 
Table 1. Means and standard deviations for performance and metabolic measuresa

\begin{tabular}{lcc}
\hline Variable & Mean & $\mathrm{SD}$ \\
\hline 1. Total work (kpm) & 2890.0 & 255.0 \\
2. Resting $\mathrm{O}_{2}$ income $(\mathrm{l} / \mathrm{min})$ & 0.32 & 0.04 \\
3. Peak net exercise $\mathrm{O}_{2}$ income $(\mathrm{l} / \mathrm{min})$ & 2.03 & 0.46 \\
4. Total $\mathrm{O}_{2}$ income (liters) & 2.35 & 0.46 \\
5. Exercise Ve BTPS (liters) & 130.5 & $\mathbf{3 4 . 2}$ \\
6. Net recovery $\mathrm{O}_{2}$ (liters) & 4.89 & 1.12 \\
7. Net recovery $\mathrm{O}_{2} / \mathrm{kg}$ (ml/kg) & 0.068 & 0.016 \\
8. Gross recovery $\mathrm{O}_{2}$ (liters) & 9.71 & 1.19 \\
9. Net $\mathrm{O}_{2}$ deficit (liters) & 1.31 & 0.47 \\
10. Net $\mathrm{O}_{2}$ deficiency (liters) & 3.58 & 1.69 \\
11. Net $\mathrm{O}_{2}$ cost of work - $\mathrm{O}_{2}$ income & & \\
+ $\mathrm{O}_{2}$ recovery (liters) & 6.93 & 1.42 \\
12. Net work efficiency (percent) & 19.3 & 3.3 \\
13. Gross work efficiency (percent) & 11.1 & 3.7 \\
14. Vo $\mathrm{o}_{2}$ Max (l/min) & 3.34 & 0.62 \\
15. Ve Max (liters) & 151.7 & 17.4 \\
\hline
\end{tabular}

a All values are for one-minute performance tests except $V_{o_{2}} \max$ and $V e$ max which were obtained on the increment bicycle test.

Since only one test was administered to each subject, the extent of performance reliability and individual differences cannot be quantified. However, in two separate experiments with a comparable work-rate and number of subjects, the writer has found high test-retest performance reliability, namely $r=0.89$ and $r=0.93$ (unpublished observations).

Table 1 gives the means and standard deviations for the observed and calculated metabolic measures during the one-minute test in addition to the $V_{\mathrm{O}_{2}} \max$ and $\max V_{e}$ obtained during the increment test. The differences between $V_{\mathrm{O}_{2}}$ max and the total $\mathrm{O}_{2}$ uptake during the oneminute test is $0.991(t=0.55, p>0.05)$ while the difference between $\max V e$ measured on the increment test and on the one-minute test is $21.21(t=7.1, p<0.01)$.

Curve Analysis. The close agreement of the theoretical curve with the experimentally determined points shown in the main part of Fig. 1 is convinaing; the theoretical formula $Y=a e^{-k t}+C$ for the $\mathrm{O}_{2}$ income and $Y=a_{1} e^{-k_{1} t}+a_{2} e^{-k_{2} t}-C$ for the $\mathrm{O}_{2}$ recovery describes the results very satisfactorily. Evidently, even under conditions where the current $\mathrm{O}_{2}$ income is inadequate (probably limited by such factors as blood supply), the rate pattern of $\mathrm{O}_{2}$ uptake is adequately described by the conventional exponential model. It should be noted that this analysis only accounts for the time pattern of $\mathrm{O}_{2}$ uptake and recovery and does 


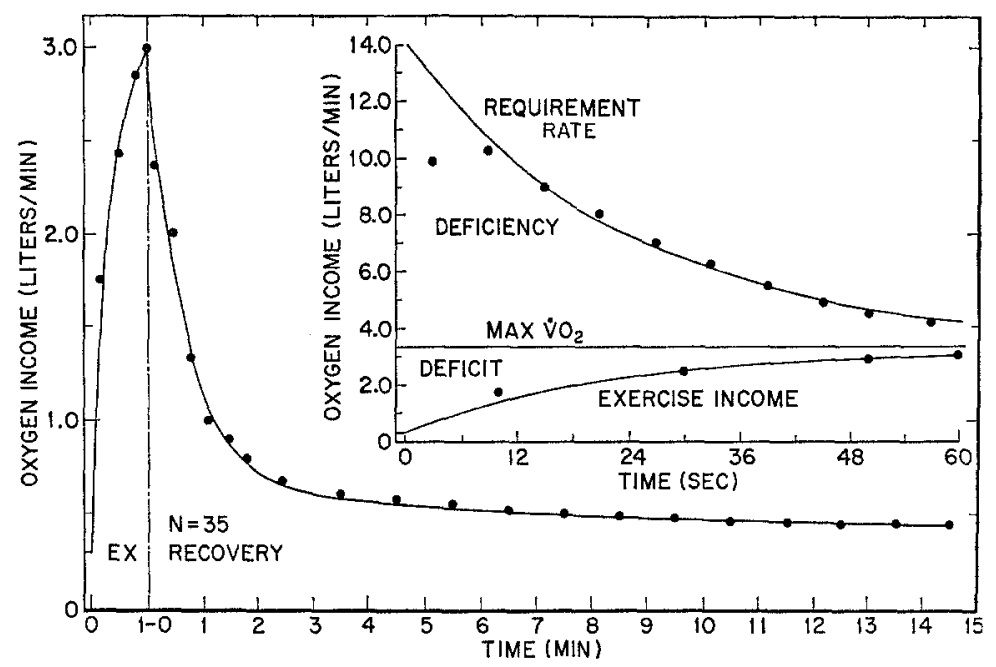

Fig. 1. Exponential oxygen uptake and recovery curves for one-minute supramaximal exercise. See text for calculation of requirement rate, deficiency and deficit shown in the insert figure

not attempt to explain or account for the time pattern of blood lactate accumulation and disappearance, or of biochemical energy production.

Note that $V_{\mathrm{O}_{2}}$ max necessarily represents the asymptotic parameter $C$ of the $\mathrm{O}_{2}$ uptake curve. The other curve parameters are $a=3.04$ and $k=2.256$. The last plotted value is not an observed point but rather corresponds to the computed value at the end of exercise and beginning of recovery. The computed half time for the exercise $\mathrm{O}_{2}$ uptake is $18.4 \mathrm{sec}$ which is similar to the value previously reported for isolated dog gastrocnemius [27], and for human subjects during the transition from mild to heavy work [8]. This corresponds to an $\mathrm{O}_{2}$ debt accumulation of $18.9 \mathrm{ml} / \mathrm{kg} \cdot \mathrm{min}$ for the present exercise which is larger than previously reported [8]. Since the exercise lasted one-minute and only three twentysecond $\mathrm{O}_{2}$ samples were taken, the fitting of the curve is limited to a one-component analysis. It should be realized that if the exercise had continued for several additional minutes two components might have emerged as it did in the experiments by Henry [9], Henry and DeMoor [14], DeMoor [7], Knuttgen [20], and Royce [28]. The exercise $k$ is roughly $11 / 2$ times greater than $k_{1}$ of recovery.

The recovery curve gives the rate of $\mathrm{O}_{2}$ uptake $Y$ at any time $t$ in excess of the resting rate established near the end of the recovery period. The terms $a_{1} e^{-k_{1} t}$ and $a_{2}{ }^{-k_{2} t}$ are the fast and slow components of the 
recovery oxygen uptake. The measured net $\mathrm{O}_{2}$ uptake for the $15 \mathrm{~min}$ recovery, using the pre-exercise resting level of $0.321 / \mathrm{min}$ as a reference, is $4.89 \mathrm{l}$. This is considerably smaller than the observed values of several investigators $[6,16,25]$ who reported data for heavy exercise, but similar to the estimate of Margaria et al. [24]. The value computed from the 2-component exponential equation using the obtained parameters for the smooth curve: $a_{1}=2.80, a_{2}=0.338, k_{1}=1.443, k_{2}=0.059$, and $C=0.30$ is 4.671 or $4.5 \%$ less than the observed $\mathrm{O}_{2}$ recovery. It should be noted that the agreement would be closer if adjustment were made to recognize that this mathematical payoff curve starts about 5 to $10 \mathrm{sec}$ at the official end of exercise. The $k$ 's of this equation correspond to half-times of $28.8 \mathrm{sec}$ for the fast component and $11.76 \mathrm{~min}$ for the slow component. Table 2 shows a comparison of these curve parameters with other data. Where only $t_{1 / 2}$ was reported, the $k$ constant was calculated. The measured value of $k$ is computed from the relationship $k=0.693 / t_{1}$, where $t_{1 / 2}$ represents the amount of time required for $\mathrm{O}_{2}$ to progress from the initial value to one-half the amount of that value. The naperian log base $e=0.693$.

The average fast component of recovery $\left(a_{1} e^{-k_{1} t}\right)$ is 1.441 or $21 \mathrm{ml} / \mathrm{kg}$ body weight. This is nearly identical to the estimated value based on blood lactate measures of Margaria et al. [24], but well under the maximum limit estimated to be 3 or 41 by Margaria and Edwards in 1934 [25]. However, the actual limit of the fast component is uncertain since the extent of individual differences has not been investigated. The fast component velocity constant $\left(k_{1}\right)$ of 1.58 appears to be within the range reported by others for much lighter work (Table 1). According to Berg [2], this fast velocity constant, $k_{1}$, is independent of workload within fairly wide limits; however, the data of Henry and DeMoor [14] shows that it becomes appreciably faster when there is a large increase in the rate of work.

In the case of the slow component of recovery, $a_{2} e^{-k_{2} t}$, the integral of the curve for $15 \mathrm{~min}$ recovery $\left(a_{2} / k_{2}-a_{15} / k_{2}\right.$, where $a_{2}=0.338$ and $a_{15}=0.145$ ) is 3.271 which is similar to the 3.01 estimate of Margaria et al. from lactate measurements [24]. The proportion of slow component recovery to total recovery is roughly $69 \%$. To determine precisely the magnitude of the recovery constant it is necessary to follow recovery for 1 to $2 \mathrm{~h}$. This necessitates that subjects remain relaxed and quiet as they approach their asymptotic resting values. It was not possible to observe these requirements in the present study. The effect of a shortened recovery time is to increase the magnitude of the $k_{2}$ constant resulting in an apparent slow component that is smaller than the true values. Since the integral for the slow component becomes $a_{2} / k_{2}$ at infinity, the calculated value of $Y$ at the asymptote $C$ yields an additional 
Oxygen Uptake and Supramaximal Work

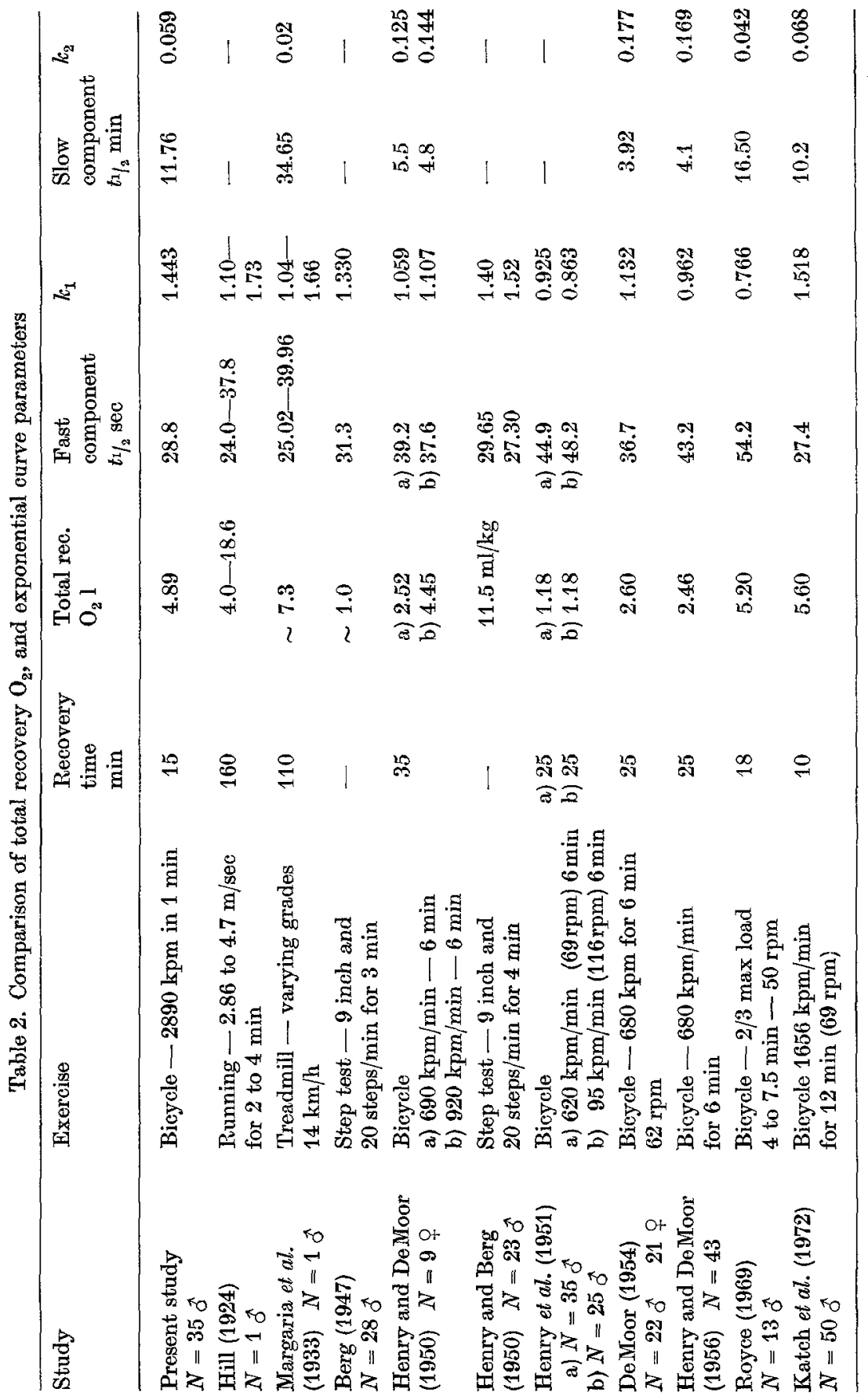


0.941 . This would result in a total net $\mathrm{O}_{2}$ recovery of 5.831 which is similar to the maximal value for surplus $\mathrm{O}_{2}$ during recovery reported by Welch et al. on their one subject [32].

The insert of Fig. 1 was constructed in order to examine the data with respect to the concept that for an extended period of time, supramaximal work (work requiring a greater $\mathrm{O}_{2}$ consumption that can be supplied by the aerobic power) decreases exponentially per-unit time approaching a level that can be maintained by the aerobic power. Shown are the curves for the $\mathrm{O}_{2}$ requirement-rate and $\mathrm{O}_{2}$ income during the exercise. $V_{\mathrm{O}_{2}} \max$ is shown as the horizontal line. The oxygen requirement-rate values are calculated as follows: The minute-by-minute work $(\mathrm{kpm} / \mathrm{min})$ is converted to equivalent by dividing the work by $2153 \mathrm{kpm}$ (1 $1 \mathrm{O}_{2}=2153 \mathrm{kpm}$ ) then dividing the $\mathrm{O}_{2}$ equivalent by the calculated efficiency (in this case $19.34 \%$, Table 1). For the total $\mathrm{O}_{2}$ requirement, for example, the $\mathrm{O}_{2}$ equivalent $(1.342 \mathrm{l}$ ) is $2.890 \mathrm{kpm}$ divided by $2153 \mathrm{kpm}$. This equivalent divided by the efficiency (0.1934) constitutes a requirement of 6.931 . These calculations are based on the assumption that the efficiency remains constant throughout work and recovery. It is possible that this assumption is not true; however, this should not change the basic analysis since the curve would approach the same asymptote ( $V_{\mathrm{O}_{2}} \mathrm{max}$ ) but only at a different rate. The term deficiency is used here to denote the difference between the $V_{\mathrm{O}_{2}} \max$ and $\mathrm{O}_{2}$ requirement-rate. This should not be confused with the deficit, which is defined as the difference between the amount of $\mathrm{O}_{2}$ consumed and the $\mathrm{O}_{2}$ uptake that would have been, had the uptake reached a steady level instantaneously. During the submaximal exercise there is no deficiency, only a deficit. The deficit plus the deficiency have often been combined and called the deficit, but when it is possible to calculate a requirement-rate curve determining the deficiency is helpful in analyzing the total oxygen debt.

The mathematical curve $Y=a e^{-k t}-C$ was used to fit the smooth curve to the calculated requirement-rate values. The curve parameters are $a=10.80, k=2.349$ and $C=3.34$ ( $V_{\mathrm{O}_{2}} \mathrm{max}$ ). The fact that this curve declines at the very instant the subject begins pedalling probably reflects the fact that physiological fatigue begins with the inititation of movement. For the present purposes, this can be considered in broad terms resulting from a decline in the biochemical release of energy, or from the accumulation of metabolites that decrease muscle energy. The net effect of this fatigue is to reduce work output per-unit time. This situation is described quite well by the above mathematioal expression.

It should be noted that the curve parameter $a$ of this requirement-rate equation theoretically represents the maximal amount of energy supply in $\mathrm{O}_{2}$ units available at the very beginning of exercise. This is equal to $14.14 \mathrm{l}$, or $70.7 \mathrm{kcal}$ which is well within the range predicted by Margaria 
et $a l$. [23] for the alactiacid $\mathrm{O}_{2}$ capacity. The fact that the first observed value is off the curve probably reflects the necessity for overcoming inertial factors, and complications caused by the sudden increase in the friction load on the flywheel.

The requirement-rate curve and $\mathrm{O}_{2}$ uptake curve have a common asymptote, $V_{\mathrm{O}_{2}} \max$; they also have similar half-times, for the requirement rate $t^{1} / 2$ is $17.5 \mathrm{sec}$ and for the $\mathrm{O}_{2}$ income curve it is $18.4 \mathrm{sec}$. It is a simple matter to calculate the time when these two curves approach a certain percentage of the asymptotic parameter $C$; in 1 min the two curves are $10 \%$ from the asymptote, $5 \%$ in $78 \mathrm{sec}$, and $1 \%$ in $2 \mathrm{~min}$. This indicates that using this work profile the subjects would have reached their $V_{\mathrm{O}_{2}} \max$ in approximately $2 \mathrm{~min}$.

Since continuation of the work beyond the 1 min would have eventually resulted in a steady state $\mathrm{O}_{2}$ uptake equal to the $V_{\mathrm{O}_{2}} \max$, when calculating the deficit according to standard methods [33] this steady state value must be used. In this case, the deficit equals 1.31 . The surplus $\mathrm{O}_{2}$ during recovery is $73 \%$ greater than this deficit, while the deficiency $(3.581)$ plus the deficit is identical with the recovery $\mathrm{O}_{2}$ uptake (Table 1).

Acknowledgements. The writer wishes to express his appreciation to Bruce Edwards for technical assistance, and F. M. Henry for statistical advise.

\section{References}

1. Alpert, N. R.: Lactate production and removal and the regulation of metabolism. Ann. N.Y. Acad. Sci. 119, 995-1012 (1965).

2. Berg, W. E.: Individual differences in respiratory gas exchange during recovery from moderate exercise. Amer. J. Physiol. 149, 597-610 (1947).

3. Brooks, G., Hittelman, K. J., Faulkner, J. A., Beyer, R. E.: Tissue temperature and whole-animal oxygen consumption after exercise. Amer. J. Physiol. 221 (2), $427-431$ (1971).

4. Christensen, E. H., Hogberg, P.: The efficiency of anaerobic work. Arbeitsphysiologie 14, 249-250 (1950).

5. Crescitelli, F., Taylor, C.: The lactate response to exercise and its relationship to physical fitness. Amer. J. Physiol. 141, 630 (1944).

6. Cureton, T. K.: Physical fitness of champion athletes. Urbana: The University of Tllinois Press 1951.

7. De Moor, J. C.: Individual differences in oxygen debt curves related to mechanical efficiency and sex. J. appl. Physiol. 6, 460-466 (1954).

8. Di Prampero, P. E., Davies, C. T. M., Cerretelli, P., Margaria, R.: An analysis of $\mathrm{O}_{2}$ debt contracted in submaximal exercise. J. appl. Physiol. 29, 547-551 (1970).

9. Henry, F. M.: Aerobic oxygen consumption and alactic debt in muscular work. J. appl. Physiol. g, 427-438 (1951).

10. Henry, F. M.: The oxygen requirement of walking and running. Res. Quart. Amer. Ass. Hith phys. Educ. 24, 169-175 (1953).

11. Henry, F. M.: Reliability, measurement error and intraindividual differences. Res. Quart. Amer. Ass. Hlth phys. Educ. 30, 21-24 (1959). 
12. Henry, F. M., Berg, W. E.: Physiological and performance changes in athletic conditioning. J. appl. Physiol. s, 103-111 (1950).

13. Henry, F. M., DeMoor, J.: Metabolic efficiency of exercise in relation to workload at constant speed. J. appl. Physiol. 2, 481-487 (1950).

14. Henry, F. M., DeMoor, J.: Lactic acid and alactic oxygen consumption in moderate exercise of graded intensity. J. appl. Physiol. 8, 608-614 (1956).

15. Henry, F. M., DeMoor, J. C., Trafton, I. R.: Individual differences in oxygen metabolism of work at two speeds of movement. Res. Quart. Amer. Ass. Hlth phys. Educ. 22, 324-333 (1951).

16. Hill, A. V., Long, C. N. H., Lupton, H.: Muscular exercise, lactic acid, and supply and utilization of oxygen, Parts IV-VI. Proc. roy. Soc. B 97, 84-138 (1924).

17. Katch, V.: Correlation vs. ratio adjustment of body weight in exercise-oxygen studies. Ergonomics 15 (6), 671-680 (1972).

18. Katch, V., Henry, F. M.: Prediction of running performance using maximal oxygen debt and intake. Med. and Sci. in Sports 4 (4), 187-191 (1972).

19. Katch, F. I., Girandola, R. N., Henry, F. M.: The influence of the estimated oxygen cost of ventilation on oxygen deficit and recovery oxygen intake for moderately heavy bicycle ergometer exercise. Med. and Sci. in Sports 4 (2), $71-76$ (1972).

20. Knuttgen, H. G.: Oxygen debt, lactate, pyruvate, and excess lactate after muscular work. J. appl. Physiol. 17, 639-644 (1962).

21. Knuttgen, H. G.: Oxygen debt after submaximal physical exercise. J. appl. Physiol. 29 (5), 651-657 (1970).

22. Margaria, R., Cerretelli, P., Aghemo, P., Sassi, G.: Energy cost of running. J. appl. Physiol. 18, 367-370 (1963).

23. Margaria, R., Cerretelli, P., diPrampero, P. E. : Energy utilization in intermittent exercise of supramaximal intensity. J. appl. Physiol. 26, 752-756 (1969).

24. Margaria, R., Cerretelli, P., diPrampero, P. E., Massari, C., Torelli, G.: Kinetics and mechanism of oxygen debt contraction in man. J. appl. Physiol. 18, 371377 (1963).

25. Margaria, R., Edwards, H. T.: The sources of energy in muscular work performed in anaerobic conditions. Amer. J. Physiol. 108, 341-348 (1934).

26. Margaria, R., Edwards, H. T., Dill, D. B.: The possible mechanism of contracting and paying the oxygen debt and the role of lactic acid in muscular contraction. Amer. J. Physiol. 106, 689-715 (1933).

27. Piiper, J., diPrampero, P. E., Cerretelli, P.: Oxygen debt and high-energy phosphates in gastrocnemius muscle of the dog. Amer. J. Physiol. 215, 523-531 (1968).

28. Royce, J.: Active and passive recovery from maximal aerobic capacity work. Int. Z. angew. Physiol. 28, 1-8 (1969).

29. Stainsby, W. N., Welch, H. G.: Lactate metabolism of contracting dog muscle in situ. Amer. J. Physiol. 211, 177-183 (1966).

30. Tanner, J. M.: Fallacy of per-weight and per-surface area standards, and their relation to spurious correlation. J. appl. Physiol. 2 (1), 1-15 (1949).

31. Wasserman, K., Burton, G. G., Van Kessel, A. L.: Interactions of physiological mechanisms during exercise. J. appl. Physiol. 22, 71-85 (1967). 
32. Welch, H. G., Faulkner, J. A., Barclay, J. K., Brooks, G. A.: Ventilatory response during recovery from muscular work and its relation with $\mathrm{O}_{2}$ debt. Med. and Sci. in Sports 2, 15-19 (1970).

33. Whipp, B. M., Seard, C., Wasserman, K.: Oxygen deficit-oxygen debt relationships during exercise. Physiologist 12, 391 (1969).

34. Whipp, B. M.: Rate constant for the kinetics of oxygen uptake during light exercise. J. appl. Physiol. 30 (2), 261-263 (1971).

Dr. V. L. Katch

Research Laboratories

Dept. of Physical Education

The University of Michigan

1100 South State Street

Ann Arbor, Michigan 48104, U.S.A. 